\title{
Fibreoptic assessment of laryngeal aperture in patients with difficult laryngoscopy
}

\author{
Ichiro Takenaka $\mathrm{MD}$, \\ Kazuyoshi Aoyama MD, \\ Tatsuo Kadoya MD, \\ Takeyoshi Sata MD, \\ Akio Shigematsu MD
}

Purpose: To determine the relationship between the area of the laryngeal aperture $(L A)$ seen fibreoptically during laryngoscopy and the difficulty of tracheal intubation in patients with difficult laryngoscopy

Methods: In 587 adult patients after induction of general anesthesia and muscle relaxation, the best laryngoscopic view of the larynx using a Macintosh 3 blade was classified according to Cormack. When the LA could not be seen, with laryngoscope blade in place, the LA view provided by a fibreoptic bronchoscope (FOB)-camera passed nasally was photographed. Then, the laryngoscopist attempted to intubate the trachea using the Macintosh blade. Tracheal intubation requiring more than three attempts was defined as difficult. After the third attempt, the trachea was intubated orally aided by FOB. The LA view after jaw thrust during FOB-aided intubation was photographed.

Results: Laryngoscopy was difficult in 17 of 587 patients. In four, intubation was difficult. In the remaining 13 patients the trachea was easy to intubate. The LA area obtained by the FOB in the difficult group (median, 0.19; intra-quartile range, 0.14 to $\left.0.39 \mathrm{~cm}^{2}\right)$ was smaller than that in the easy group $\left(2.43 ; 1.84\right.$ to $\left.2.93 \mathrm{~cm}^{2}\right)(P=$ 0.003 ). In contrast, the $L A$ area provided by jaw thrust during the FOB-aided intubation in the difficult group (2.28; 1.99 to $2.73 \mathrm{~cm}^{2}$ ) was similar to that during laryngoscopy in the easy group.

Conclusion: Inability of the laryngoscope to provide an adequate LA view is one cause of difficult intubation with the Macintosh laryngoscope in patients with difficult laryngoscopy.

Objectif : Déterminer la relation entre la zone d'ouverture laryngienne $(\mathrm{O})$ décelée pendant la laryngoscopie fibroscopique et la difficulté d'intubation endotrachéale chez des patients dont la laryngoscopie est difficile.

Méthode : Après l'induction de l'anesthésie générale et la curarisation chez 587 adultes, la meilleure vision laryngoscopique du larynx obtenue avec une lame de Macintosh 3 a été classée selon Cormack. Quand on ne pouvait visualiser l'OL à partir de la lame du laryngoscope en place, on a photographié l'OL obtenue avec une caméra de fibroscope bronchique (FOB) introduite par voie nasale. Ensuite, on a tenté l'intubation endotrachéale avec la lame Macintosh. L'intubation qui nécessitait plus de trois essais était jugée difficile. Après le troisième essai, l'intubation était réalisée par voie orale avec le FOB. On a photographié l'OL après la subluxation de la mâchoire pendant l'intubation facilitée par le FOB.

Résultats : La laryngoscopie a été difficile chez 17 patients et l'intubation a été difficile chez 4 d'entre eux. La zone d'OL obtenue à l'aide du FOB dans le groupe à intubation difficile (médiane, 0,19 ; intervalle intra-quartile, 0,14 à $\left.0,39 \mathrm{~cm}^{2}\right)$ était plus petite que celle du groupe à intubation facile $\left(2,43 ; 1,84\right.$ à $\left.2,93 \mathrm{~cm}^{2} ; P=0,003\right)$. Par ailleurs, l'OL obtenue par la subluxation de la mâchoire, pendant l'intubation facilitée par le FOB dans le groupe difficile $\left(2,28 ; 1,99\right.$ à $\left.2,73 \mathrm{~cm}^{2}\right)$, était similaire à celle qu'on a obtenue pendant la laryngoscopie dans le groupe facile.

Conclusion : L'impossibilité du laryngoscope de fournir une vision valable de l'OL est l'une des causes de l'intubation difficile avec le laryngoscope Macintosh chez des patients dont la laryngoscopie est difficile.

From the Department of Anesthesiology, School of Medicine University of Occupational and Environmental Health, 1-1 Iseigaoka Yahatanishi-ku Kitakyushu 807-8555, Japan.

Address correspondence to: Ichiro Takenaka, Phone: 93-691-7265; Fax: 93-601-2910

Accepted for publication December 19, 1998 
$\mathrm{T}$

HE direct laryngoscopic view is commonly used to evaluate the degree of tracheal intubation difficulty because of the ease in making objective assessments. ${ }^{1}$ However, in some patients in whom the glottis cannot be scen during laryngoscopy the trachea can still be intubated when an endotracheal tube (ETT) is advanced behind the epiglottis blindly. ${ }^{2,3}$ Difficult laryngoscopy (failure to see the glottis) is not synonymous with difficult intubation. No studies have identified the cause of the difference between difficult laryngoscopy and difficult intubation.

The structures of the laryngeal aperture (LA) during laryngoscopy are important anatomical landmarks when an ETT is inserted into the trachea. During general anesthesia with/without muscle relaxation, any loss of tone in the laryngeal muscles causes collapse of the LA. ${ }^{4}$ Application of the laryngoscope enables the trachea to be intubated by expanding the collapse and visualizing the LA. Sometimes, blind probing is employed to intubate the trachea when, during laryngoscopy, the LA is not seen under direct vision. In this case, when the tip of the ETT is introduced into the LA blindly, the ETT will fall into the glottic opening and the trachea because of the funnel shape of the larynx. If the laryngoscope does expand the collapse of the LA fully, even when the LA is invisible, it is easy to advance the ETT blindly into the LA, and the likelihood of successful passage of the ETT into the trachea is increased. One of the causes for the difference between difficult laryngoscopy and difficult intubation may be that the LA area provided by the laryngoscope, and which is obtained using a fibreoptic bronchoscope (FOB), is reduced. The aim of this scudy is to examine the relationship between the area of the LA seen fibreoptically during laryngoscopy and the degree of tracheal intubation difficulty in patients with difficult laryngoscopy.

\section{Methods}

\section{Clinical study}

Following approval from the Institutional Ethical Committee and informed consent, we studied 596, ASA 1-2, adult patients requiring general anesthesia and tracheal intubation for elective non-obstetric surgery. The exclusion criteria included morbid obesity, cervical spine pathology, pharyngo-laryngeal pathology, and an increased risk of aspiration.

All patients received $0.25 \mathrm{mg}$ triazolam po two hours before induction of anesthesia. The patients lay supine on the operating table and a pillow and blanket were placed under the occiput to achieve an optimal "sniffing position". 5-7 Standard monitors were applied. General anesthesia was induced with $4 \mathrm{mg} \cdot \mathrm{kg}^{-1}$

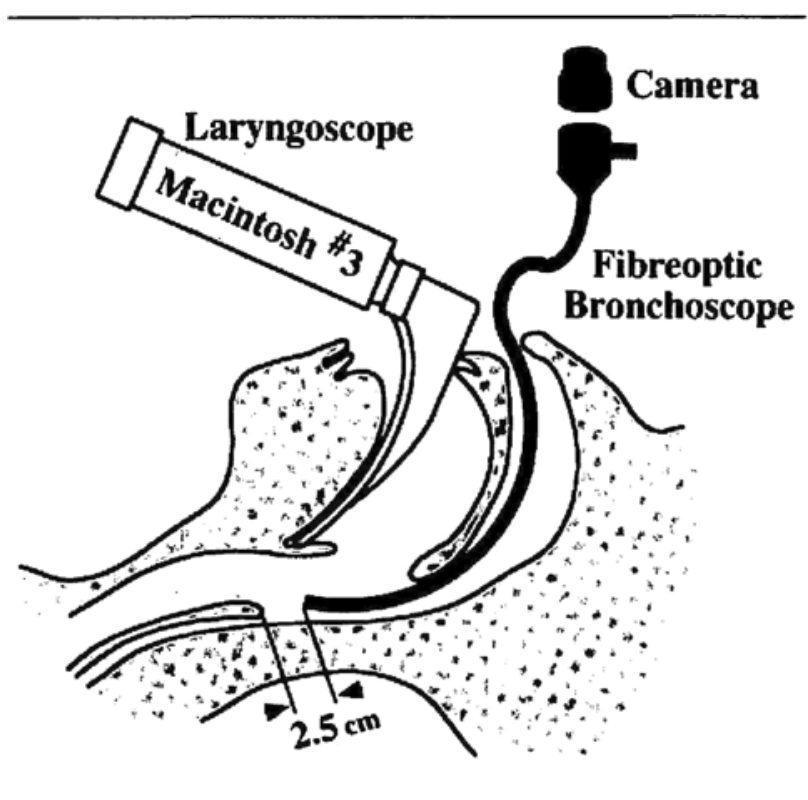

FIGURE 1 Assessment of the laryngeal aperture area during laryngoscopy.

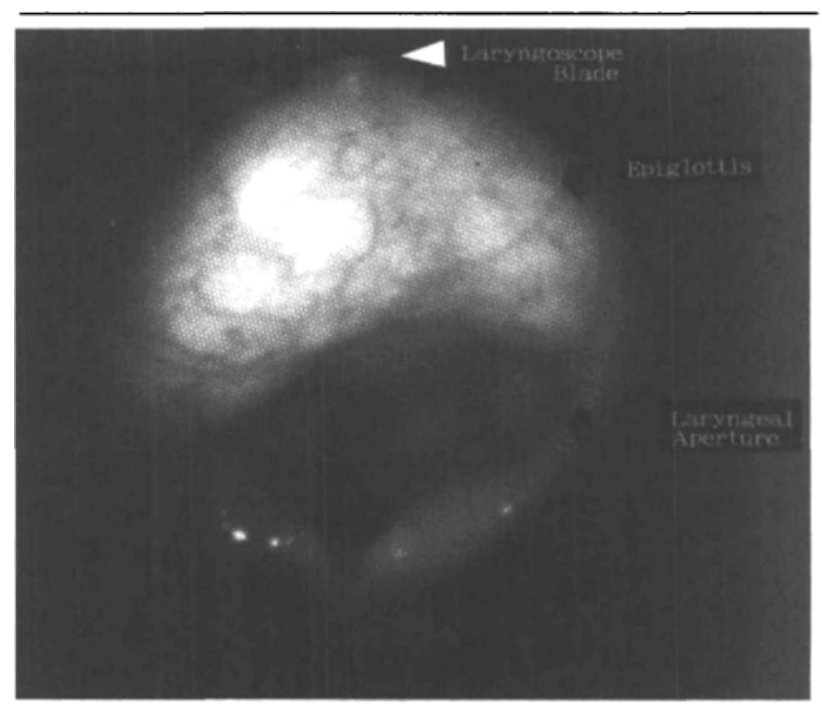

FIGURE 2 Fibreoptic view of the laryngeal aperturc (LA) during laryngoscopy in a patient with difficult laryngoscopy. The trachea was easy to intubate. The LA area; $3.6 \mathrm{~cm}^{2}$.

thiopental ip and muscle relaxation was produced with $0.1 \mathrm{mg} \cdot \mathrm{kg}^{-1}$ vecuronium. The patient's lungs were ventilated with sevoflurane $2-4 \%$ in oxygen via a face mask until the train-of-four response evoked by ulnar nerve stimulation was abolished.

The assessment of the laryngoscope-provided LA area was based on the method that we described previously ${ }^{8}$ (Figure 1). Briefly, after the mask was removed, one 


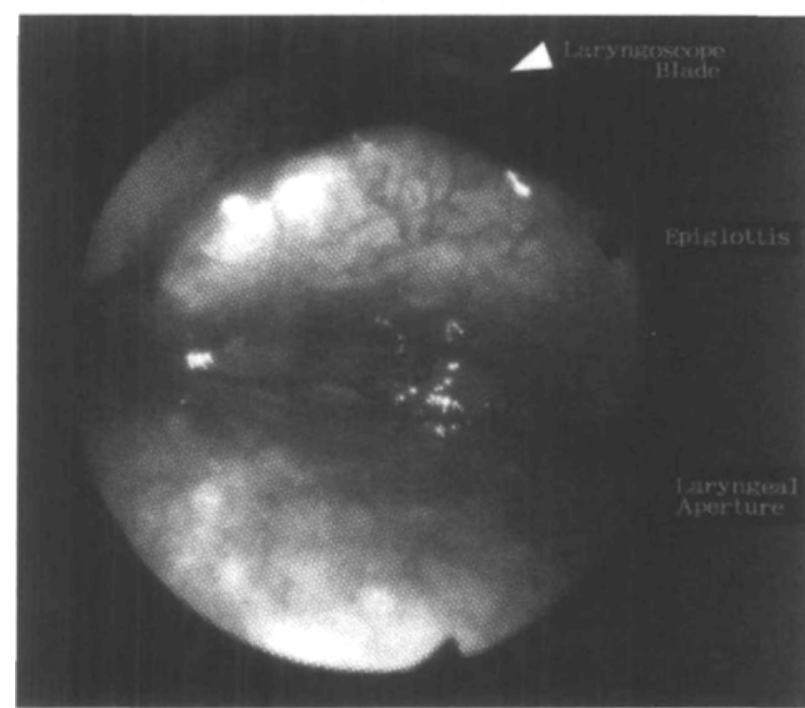

FIGURE 3 Fibreoptic vicw of the laryngeal aperture (LA) during laryngoscopy in a paticnt with difficult laryngoscopy. The trachea was intubated using the FOB-aided method. The LA area; $0.1 \mathrm{~cm}^{2}$.

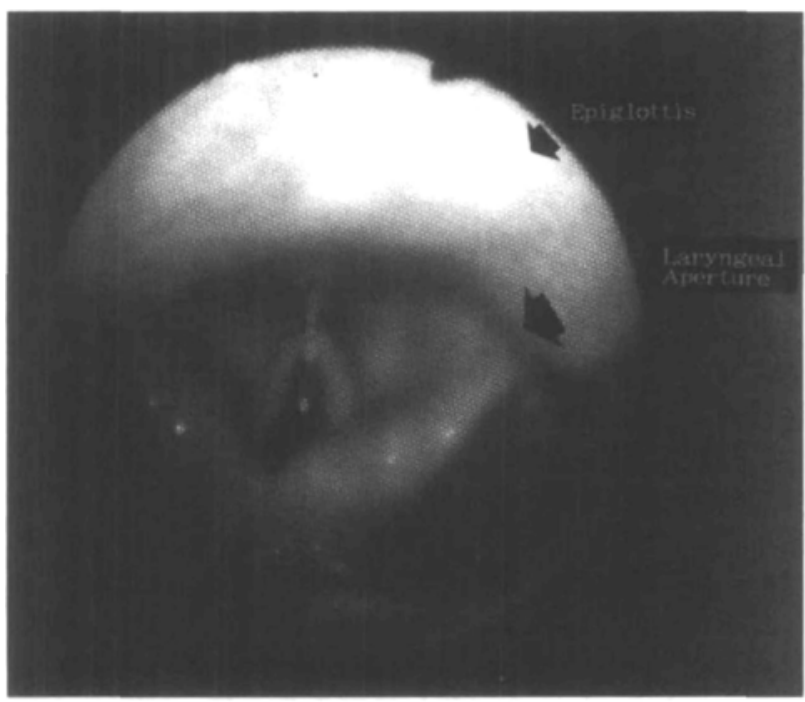

FIGURE 4 Fibreopric view of the laryngeal aperture (LA) during jaw thrust manoeuvre in the same patient as in Figure 3 . The LA area; $2.9 \mathrm{~cm}^{2}$.

laryngoscopist (IT), an experienced anesthesiologist, fully exposed laryngeal structures to the best of his ability using a Macintosh 3 blade. External laryngeal manipulation was applied when necessary. The laryngoscopist then assessed the laryngoscopic view using the classification described by Cormack and Lehane, ${ }^{1}$ where grade 1
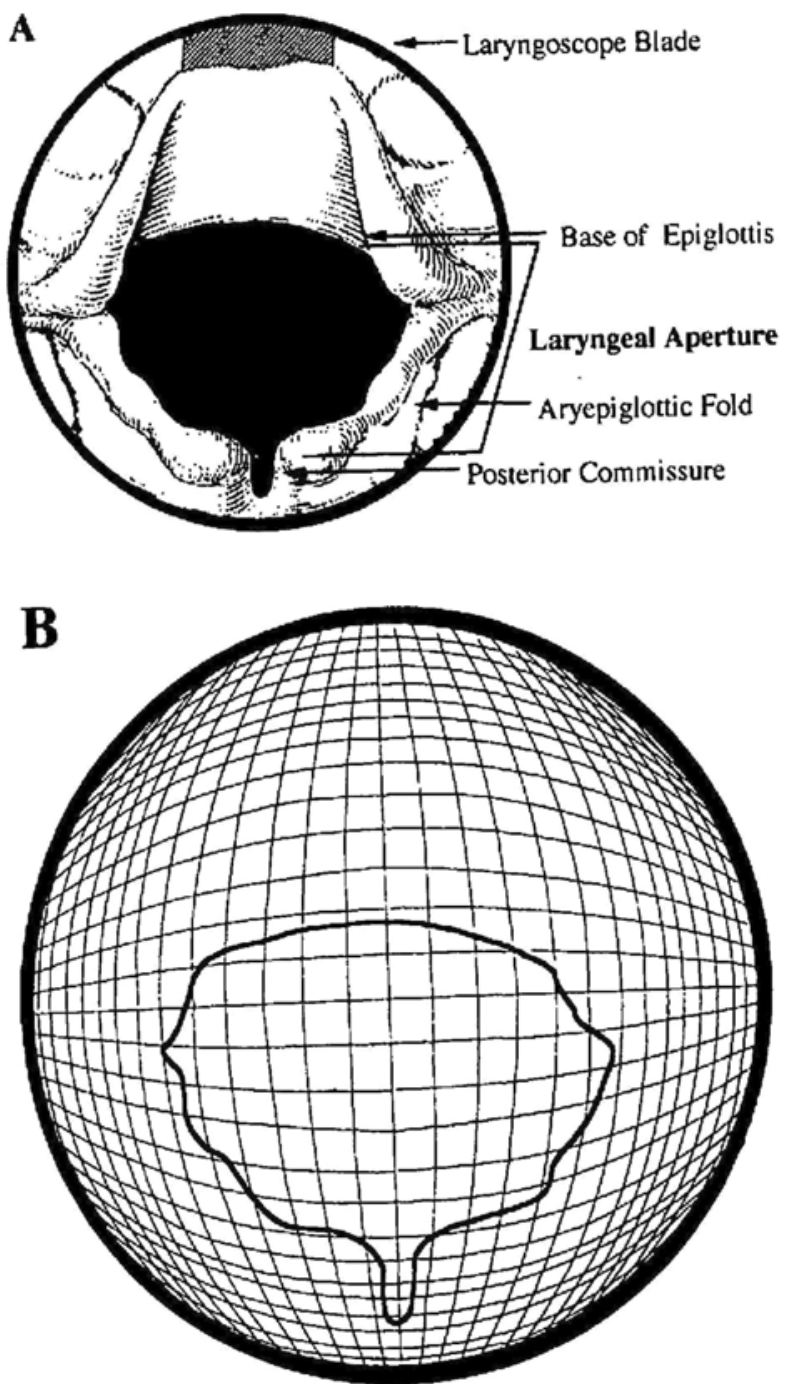

FIGURE 5 (A); Diagram showing the fibreoptic view of the laryngeal aperture (the shaded area) photographed during laryngoscopy. (B); Method of measuring the laryngeal aperture area using $2.5 \times 2.5 \mathrm{~mm}$ graph paper.

= the entire LA was seen; grade $2=$ only the posterior portion of the LA was seen; grade $3=$ only the epiglottis was seen; grade $4=$ even the epiglottis was obscured. Laryngoscopic grades 3 and 4 were defined as difficult. Then, in patients with grade 3 or 4 laryngoscopic view, with the laryngoscope blade still in place, an endoscopist, who was one of two experienced anesthesiologists, passed a $4.9 \mathrm{~mm}$ FOB (BF-P30 Olympus, Tokyo, Japan) attached to a camera (SC16-10 Olympus) through the nasopharynx. The FOB was advanced behind the epiglottis and positioned just proximal to the surface of 
the arytenoid cartilage during insufflation with oxygen via the working channel. The FOB was marked at that point. The tip of the FOB was then withdrawn to $2.5 \mathrm{~cm}$ from the mark using a ruler to obtain a view of the entire larynx. The view of the LA provided by the Macintosh laryngoscope was photographed using the FOB-camera (Figures 2, 3), and then the FOB was removed. Following laryngoscopy and photography, the laryngoscopist attempted to insert a $7.0 \mathrm{~mm}$ or $7.5 \mathrm{~mm}$ internal diameter ETT, equipped with a stylet, into the trachea. When the first or second attempt at intubation failed, the head and neck position and curvature of the distal end of the ETT were changed. The laryngoscope blade was not changed. Difficult intubation was defined as ETT insertion that required > three attempts at laryngoscopy. ${ }^{9}$ When the third attempt at intubation failed, the laryngoscope blade was removed and the trachea was intubated orally using the FOB-video camera-aided method described below. When the jaw thrust manouevre was fully applied to facilitate exposure of the LA, the view of the LA was again photographed under the same conditions (Figure 4). After photography, the camera attached to the FOB was changed for a video camera monitor system (OTV-F3 Olympus) and a view of the larynx was displayed on the television screen. Then, the ETT with stylet was inserted into the mouth with the jaw pulled forward and advanced into the trachea under video visual control.

Reliability of the fibreoptic view of the laryngeal aperture One of two endoscopists photographed the view of the LA using the FOB-camera. To evaluate the interendoscopist variability of the fibreoptic view of the

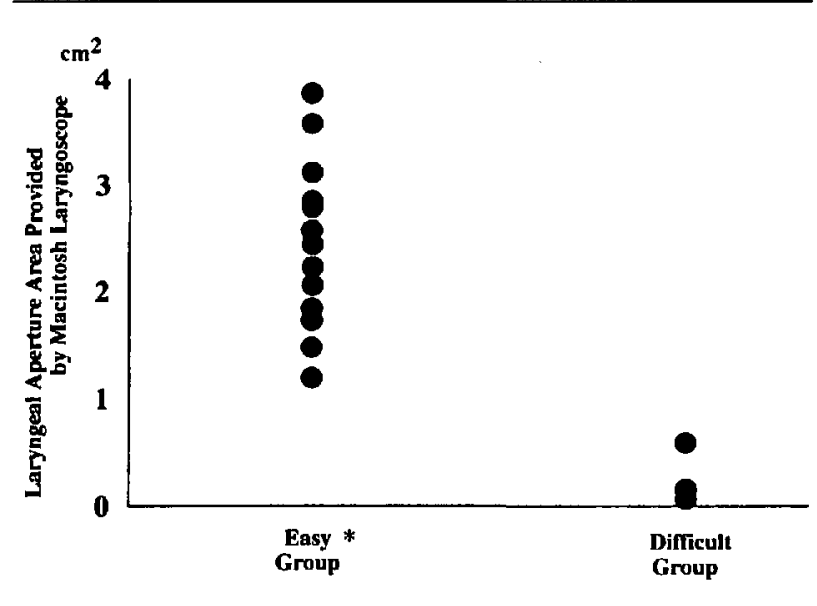

FIGURE 6 Comparison of the area of the laryngeal aperture provided by the Macintosh laryngoscope in parients with difficult laryngoscopy between the difficult $(n=4)$ and easy groups $(n=13)$ * $: P<0.01$ versus the difficult group (Mann-Whitney U test).
LA, two endoscopists separately photographed the view of the laryngoscope-provided LA on a single patient in ten consenting patients with ASA 1 in the same conditions of this study.

\section{Measurement of the laryngeal aperture area}

The LA area was defined as the area surrounding the inner surfaces of the arytenoid cartilages, the aryepiglottic folds, the posterior commissure, and the base of the epiglottis (Figure 5A). To measure the LA area, $2.5 \times 2.5 \mathrm{~mm}$ graph paper was placed $2.5 \mathrm{~cm}$ away from the tip of the FOB and was photographed. Then, an operator, unaware of the results of direct laryngoscopy and of the ease or difficulty in tracheal intubation, copied the contours of the LA and the outer boundaries of the bronchoscopic view from the photograph at laryngoscopy onto the transparent film. This film and the photograph of the graph paper were duplicated on the computer image using a scanner and both outer boundaries of the bronchoscopic view were superimposed (Figure 5B). The number of squares within the contours of the LA were counted. Two operators independently measured the LA area twice.

\section{Statistical analysis}

In each group, the LA areas were compared using Mann-Whitney $U$ test. The reliability of the fibreoptic view of the LA by the two endoscopists was tested using an interclass correlation coefficient and bias analysis. ${ }^{10} \mathrm{~A} P$ value $<0.05$ was considered statistically significant.

\section{Results}

Reliability of the fibreoptic view of the laryngeal aperture by two separate endoscopists

Of the 10 patients, nine had laryngoscopic grade \#1 and one had \#2. Bias analysis demonstrated that the mean bias was $0.036 \mathrm{~cm}^{2}$ with a $95 \%$ confidence interval -0.94 to $1.02 \mathrm{~cm}^{2}$ and an intra-class correlation coefficient of 0.90 was calculated, indicating good reliability.

\section{Difficult laryngoscopy and difficult intubation}

Nine of 596 patients (1.5\%) were excluded: two had atlanto-axial subluxation, three patients were morbidly obese, and four had pharyngo-laryngeal pathology. The remaining 587 patients were studied. Airway control was good in all patients and peripheral oxygen saturation did not decrease below $95 \%$ in any patient.

Of the 587 patients, 570 were graded 1 or 2 at laryngoscopy, and in all the tracheas were intubated easily. Grade 3 laryngoscopic views were seen in 17 $(2.9 \%)$ patients. No patient was graded 4 at laryngoscopy. External laryngeal manipulation was per- 
formed in all grade 3 patients. In 13, the ETT was passed into the trachea easily by blind probing despite the LA being invisible under direct vision (easy group). In the remaining four patients, we could not intubate the trachea using the Macintosh laryngoscope (difficult group).

\section{Laryngoscope-provided laryngeal aperture area and degree of intubation difficulty in patients with diffi- cult laryngoscopy}

The laryngoscope-provided LA areas in the easy group and the difficult group were $2.43 \mathrm{~cm}^{2}$ (median, intraquartile range, 1.84 to 2.93$)$ and $0.19 \mathrm{~cm}^{2}(0.14$ to 0.39 ), respectively. The laryngoscope-provided LA area in the difficult group was smaller than that in the easy group ( $P=0.003$, Mann-Whitney $\mathrm{U}$ test), (Figure 6 ). When the jaw thrust manouevre was applied fully during the FOB-aided intubation in the difficult group, the $\mathrm{LA}$ area provided by the manouevre was $2.28 \mathrm{~cm}^{2}$ (1.99 to 2.73) and was as large as the LA area during laryngoscopy in the easy group.

\section{Discussion}

Our findings demonstrated that only four of the 17 patients with difficult laryngoscopy had a trachea which was difficult to intubate. Thus, difficult laryngoscopy is not synonymous with difficult intubation. Among the patients with difficult laryngoscopy, the trachea was difficult to intubate when the LA area provided by the laryngoscope was small. In contrast, if the laryngoscope could provide a larger LA area, the ETT passed easily through the LA into the trachea when the tip of the ETT was advanced along the laryngeal surface of the epiglottis by blind probing. These findings indicate that the likelihood of successful intubation is increased even when the LA is invisible under direct vision if the laryngoscope can provide adequate area of the LA. Thus, one reason for the difference between difficult laryngoscopy and difficult intubation is the size of the laryngoscope-provided LA area.

In about a quarter of patients with difficult laryngoscopy, the LA area provided by the laryngoscope was very small and the trachea could not be intubated using the Macintosh laryngoscope. Thus, when the LA during laryngoscopy cannot be seen under direct vision, many repeated attempts at intubation by blind probing should be avoided to prevent airway injury. Alternative strategies for tracheal intubation may be required in this situation. ${ }^{6,9}$ In contrast to the small LA seen during laryngoscopy in patients with difficult intubation, the LA area increased when a jaw thrust manouevre was applied. In addition, their lungs were ventilated easily via the face mask after intubation attempt failed.
Therefore, their LA was not small, either anatomically or pathologically, but the Macintosh laryngoscope could not expand the LA collapse resulting from the induction of anesthesia and muscle relaxation. One possible explanation for the different LA area seen during laryngoscopy and during a jaw thrust manouevre in patients with difficult intubation may be that the direction of the force applied to the Macintosh laryngoscope differs from that required to lift the laryngeal soft tissues and the epiglottis. Even if the tip of the laryngoscope blade is placed correctly in the vallecula, the laryngoscope may not exert force on the hyo-epiglottic ligament. On the contrary, a jaw thrust manouevre may lift the laryngeal soft tissues by applying the force in a different direction from that applied by the laryngoscope blade. Another explanation is that the attempt at laryngoscopy or insertion of the FOB induces laryngospasm resulting from inadequate anesthesia and/or muscle relaxation. However, laryngospasm did not occur in our patients because adequate anesthesia and full muscle relaxation were confirmed using an anesthetic gas monitor and a nerve stimulator.

There are several potential limitations of our study with respect to experimental design. First, we only measured the laryngoscope-provided LA area at the first attempt at laryngoscopy. There may have been variation in the LA area between attempts at intubation, because the head and neck position was changed when intubation failed. We tried to obtain the optimal head and neck position in all patients prior to the first attempt at laryngoscopy. Therefore, we believe that the variation of the LA area was of little importance. Second, the laryngoscopic grade in all patients was determined by one laryngoscopist and was not confirmed by a different laryngoscopist. However, because the laryngoscopist, with an experience of $12 \mathrm{yr}$, obtained the best view, we are confident that the laryngoscopic grade was assessed objectively. Third, our results are applicable only to patients with difficult laryngoscopy using the Macintosh laryngoscope. The laryngoscope-provided LA area may increase if alternative laryngoscope blades are used. Fourth, our study does not apply to patients with pathological abnormality of the upper airway, such as laryngeal tumour or tracheal stenosis. Fifth, the laryngoscope- provided LA area is not the only determinant in successful tracheal intubation in patients with difficult laryngoscopy. Finally, it should be emphasized that the trachea may not be impossible to intubate using the Macintosh laryngoscope even when the laryngoscope- provided LA area is very small. If, in this situation, the tapered tip of the ETT can be introduced accurately into the LA, the ETT will spread the LA and will advance into the trachea because the LA is not small 
anatomically or pathologically. It is only difficult to introduce the ETT into the LA blindly.

In summary, the inability of the laryngoscope to provide adequate LA area is one cause of difficult tracheal intubation in patients with difficult laryngoscopy.

\section{References}

1 Cormack RS, Lebane J. Difficult tracheal intubation in obstetrics. Anaesthesia 1984; 39: 1105-11.

2 Williams KN, Carli F, Cormack RS. Unexpected, diffcult laryngoscopy: a prospective survey in routine general surgery. Br J Anaesth 1991; 66: 38-44.

3 Benumof JL. Difficult laryngoscopy: obtaining the best view (Editorial). Can J Anaesth 1994; 41: 36I-5.

4 Murashima $K$, Fukutome $T$. Effect of jaw-thrust manoeuvre on the laryngeal inlet. Anaesthesia 1998; 53: 203-4.

5 Horton WA, Faby L, Charters P. Defining a standard intubating position using "angle finder". Br J Anaesth 1989; 62: 6-12.

6 Benumof $J L$. Management of the difficult adult airway. With special emphasis on awake tracheal intubation. Anesthesiology 1991; 75: 1087-110.

7 Benumof JL. Conventional (laryngoscopic) orotracheal and nasotracheal intubation (single-lumen tube). In: Benumof JL (Ed.). Airway Management. Principles and Practice, lst ed. St. Louis: Mosby, 1995: 261-76.

8 Aoyama K, Takenaka I, Sata T, Shigematsu A. Use of the fibrescope-video camera system for difficult tracheal intubation. Br J Anaesth 1996; 77: 662-4.

9 A report by the American Society of Anesthesiologists Task Force on management of the difficult airway. Practice guidelines for management of the difficult airway. Anesthesiology 1993; 78: 597-602.

10 Bland JM, Altman DG. Statistical methods for assessing agreement between two methods of clinical measurement. Lancet 1986; 1: 307-10. 